\title{
Comparison of efficacy of needling and a combination of needling and platelet rich plasma in relieving pain and improving function in patients of tennis elbow: a prospective, randomized, double blinded, placebo controlled clinical trial
}

\author{
Vikram Sharma*, Vivek Chandak
}

Department of Orthopaedics, KD medical college and hospitals, Mathura, U.P, India

\author{
Received: 30 July 2020 \\ Revised: 04 October 2020 \\ Accepted: 05 October 2020 \\ *Correspondence: \\ Dr. Vikram Sharma, \\ E-mail: vikramsharma2000@gmail.com
}

Copyright: () the author(s), publisher and licensee Medip Academy. This is an open-access article distributed under the terms of the Creative Commons Attribution Non-Commercial License, which permits unrestricted non-commercial use, distribution, and reproduction in any medium, provided the original work is properly cited.

\begin{abstract}
Background: Lateral epicondylitis is a common musculoskeletal disorder for which an effective treatment strategy remains unknown. Aim of the study was to examine whether a single injection of platelet-rich plasma (PRP) with needling is more effective than needling with placebo in reducing pain in adults with lateral epicondylitis. Study design used was randomized controlled trial.

Methods: A total of 66 patients with chronic lateral epicondylitis were randomized $(1: 1)$ to receive either a blinded injection of PRP (group A) or saline (placebo) group B. The primary end point was a change in pain using the VAS and patient-rated tennis elbow evaluation (PRTEE) questionnaire. The secondary outcome being improvement in function (PRTEE scores).

Results: The VAS score and PRTEE score improved significantly in both the groups at all 3 follow-up examinations. Group A had significantly better results than the group B.

Conclusions: PRP injection are safe and effective management strategy for lateral epicondylitis
\end{abstract}

Keywords: Tennis elbow, Lateral humeral epicondylitis, Tendinopathy, Growth factors, Platelet-rich plasma, Needling

\section{INTRODUCTION}

Lateral epicondylitis, initially described in 1883 as "lawntennis elbow" and later named "tennis elbow" (TE), is the most commonly diagnosed elbow condition. ${ }^{1,2}$ Epidemiological studies describe a prevalence of $1-3 \%$ in general population, with some reports describing data up to $10 \%$ in women. ${ }^{3,4}$ It is a very painful and disabling condition. Pain with resisted wrist extension and tenderness over lateral epicondyle are the characteristic complaints of patients who present with this condition. This pain has been ascribed to microtears within the extensor carpi radialis brevis muscle and the subsequent development of angio-fibroblastic dysplasia. ${ }^{5}$ Other theories about the source of the pain include altered neurogenic pathways and up-regulation of substance $p .^{6,7}$

A wide variety of treatments has been proposed to treat this condition. First line interventions include rest, activity or equipment modification, nonsteroidal anti-inflammatory medication, bracing, and physical therapy. ${ }^{8}$ In cases not responding to these measures, second-line treatments such as cortisone injections, prolotherapy, autologous blood injections, platelet-rich plasma (PRP) injections and needling of the extensor tendon origin have been recommended.

Platelets which are a part of coagulation process, also contain more than 300 bioactive cytokines and growth factors that 
act via autocrine and paracrine mechanisms to help coordinate cellular communication. ${ }^{9}$ Platelets also release vasoactive substances such as serotonin, calcium, histamine and adenosine via their dense granules. ${ }^{10,11}$ Importantly, several studies suggest that PRP enhances human tendon cell proliferation, differentiation, and maturation. ${ }^{12-15}$ Initial clinical studies by Mishra et al showed that there were statistically significant improvements in patients treated with PRP compared with an active control group (bupivacaine with epinephrine) at 8 weeks and a 93\% reduction in pain scores for the PRPtreated patients at an average of 25.6 months. ${ }^{15}$

Other studies by Gosens and Peerbooms et al compared the effects of PRP with cortisone in prospective, randomized trials. ${ }^{17,18}$ At 2 years, the PRP-treated patients reported an improvement of $69 \%$ in pain scores compared with only $36 \%$ for patients treated with corticosteroid injections. When the patients were evaluated via the disabilities of the arm, shoulder and hand (DASH) scores at 2 years, the PRP group had an improvement of $67.6 \%$ compared with $15.7 \%$ in the cortisone group. Overall, however, these 2 controlled studies reported no safety issues and supported the use of PRP as an alternative to surgery. These studies also clearly showed that cortisone has little or no long-term value in the treatment of chronic tennis elbow.

Needling of the extensor tendon under a local anesthetic has been described in the literature as an effective treatment for chronic tennis elbow. ${ }^{19}$ Our study was designed to evaluate the efficacy of needling with and without PRP as a treatment for tennis elbow. We tested the hypothesis that the addition of PRP would result in more improvement in pain, function and lower levels of tenderness at the elbow compared with needling alone.

\section{METHODS}

This is a prospective, double blinded, placebo controlled randomized clnical study. It was done at $\mathrm{KD}$ medical college, Mathura. The study was approved by institutional ethical committee and was performed based on principles established under declaration of Helsinki and a written informed consent was taken from all the patients. All the patients suffering from tennis elbow, who attended the outpatient's department between July 2019 to December 2019 and failed to respond to conservative methods were included in this study.

The following inclusion criteria were employed: 1 . Pain by palpation at the lateral epicondyle of the elbow. 2. Baseline elbow pain score of $50 \mathrm{~mm}$ out of $100 \mathrm{~mm}$ using a visual analog scale (VAS) during resisted wrist extension. 3. History of elbow pain for at least 3 months, 4. Pain unresponsive to conservative treatment which physiotherapy and medications

The following exclusion criteria were employed: 1 . Pregnancy, 2. age $<18$ years, 3 . history of anemia and 4 . history of bleeding disorder, systemic disorders such as diabetes, hypothyroidism, rheumatoid arthritis, previous surgery for elbow tendinosis, History of arthritis or fracture of the affected elbow and received local steroid injections in the affected elbow.

The diagnosis was verified in all patients by the same physician, who also performed the inclusion, randomization, and treatment procedures. Another masked study physician, the same in all patients during the entire follow-up, was responsible for outcome assessments at 6 weeks, 3 months and 6 months. Randomization was performed before procedure using a computer generated, blocked random-allocation sequence with a 1:1 ratio. Patients and data analysis team were blinded from the study. A sealed opaque envelope was attached to the file of the patient with the name of the drug to be given during the procedure. Baseline VAS scores and PRTEE scores were recorded. Intervention was done in the form of group A: needling and PRP injection, group B: needling and placebo (saline) and PRP preparation and procedure technique.

All the patients were blindfolded during blood sampling and while receiving the intervention. Approximately 30 $\mathrm{mL}$ of whole blood was drawn from a peripheral vein of each patient. In the PRP group, the blood was mixed with an anticoagulant (ACD-A) and placed into a sterile separator canister. The canister was then placed in a desktop-sized centrifuge and processed for 15 minutes at $3200 \mathrm{rpm}$. This method of preparation produces type 1A PRP (leukocyte-enriched PRP with platelets 5 times of baseline used in an inactivated manner). The PRP was then removed and buffered to physiological $\mathrm{pH}$ using $8.4 \%$ sodium bicarbonate to neutralize the acidic ACD-A in the PRP.

The injection site was blocked using $0.5 \%$ bupivacaine with epinephrine, and then, 2 to $3 \mathrm{~mL}$ of the prepared PRP was injected into the extensor carpi radialis brevis tendon and surrounding area using a peppering technique. This technique consisted of 5 penetrations of the tendon as the PRP was injected via a single skin penetration. The control group was injected with 2 to $3 \mathrm{~mL}$ of saline using the same peppering technique as the PRP group.

\section{Post procedure protocol}

Immediately after the injection, the patient was kept in a supine position without moving the arm for 15 minutes. Patients were sent home with instructions to limit their use of the arm for approximately 24 hours. After 24 hours, patients were given a standardized stretching protocol to follow for 2 weeks. A formal strengthening program was initiated after this stretching. At 4 weeks after the procedure, patients were allowed to proceed with normal activities as tolerated.

Patients were followed up at 6 weeks, 12 weeks, and 6 months, after the index procedure. A $100-\mathrm{mm}$ visual analog pain score ( 0 , no pain; 100 , worst pain possible) and PRTEE (20) were used as outcome measures.

The patient-rated tennis elbow evaluation (PRTEE) 
consists of two sections investigating pain and function. All questions are scored on a 10-point scale. The pain section has four questions that rate the pain from 'no pain' to 'worst ever'. In addition, there is a question that rates how often the patient has pain ('never' to 'always'). The scale for function questions ranges from 'no difficulty' to 'unable to do'. The function section has 11 questions regarding specific activities of daily living, and four questions regarding personal care, household work, occupational work and recreational activities. Higher scores represent worse functioning. SPSS software was used to analyses recorded data where required.

\section{RESULTS}

66 patients satisfied our criterion. Mean duration of symptoms was 18 (range-12 to 104) weeks. 33 patients were randomly allocated to each group.

Table 1: Demographic data on 66 patients enrolled for the study.

\begin{tabular}{|llll|}
\hline Variables & Group A & Group B & Mean \\
\hline Age (years) & 43.3 & 42.7 & 43 \\
\hline Sex- M/F & $10 / 23$ & $12 / 21$ & \\
\hline BMI (kg/m (2) $^{\text {DMr }}$ & 26.2 & 25.8 & 26 \\
\hline $\begin{array}{l}\text { Duration of } \\
\text { symptoms } \\
\text { weeks }\end{array}$ & 17 & 19 & 18 \\
\hline
\end{tabular}

Of the 66 who were followed, 58 out of $66(87.8 \%)$ completed the entire 6-month program. $8(12.1 \%)$ patients did not complete the treatment due to perceived failure. Of these 5 patients were from group A, 3 from group B. These 8 patients were excluded from the final analysis.

Tennis Elbow- $\mathrm{n}=66$ Patients, male-22, female-44

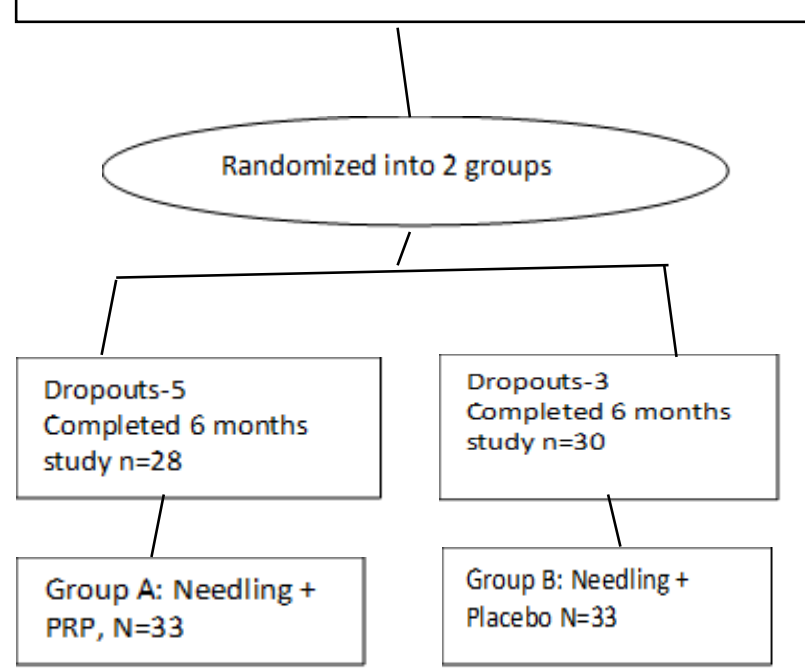

Figure 1: Flowchart depicting patient's selection.
Mean value of VAS scores in group A were 82.3 at 0 weeks, 45.6 at 6 weeks (p value 0.0036), 35.2 at 12 weeks (p value 0.001 ) and 28.8 at 24 weeks (p value 0.0014 ) while those in group B were 86 at 0 weeks, 73.2 at 6 weeks, 71.3 at 12 weeks and 63.2 at 24 weeks.

Patients also showed improvement in terms of PRTEE scores. In group A it decreased from 51.3 at 0 weeks to 23.5 at 6 weeks ( $\mathrm{p}$ value 0.0034 ) to 16.7 at 12 weeks ( $\mathrm{p}$ value 0.004 ) and 15.3 at 24 weeks (p value 0.002 ) while those in group B were 53.7 at 0 weeks to 35.5 at 6 weeks to 31.3 at 12 weeks and 27.7 at 24 weeks.

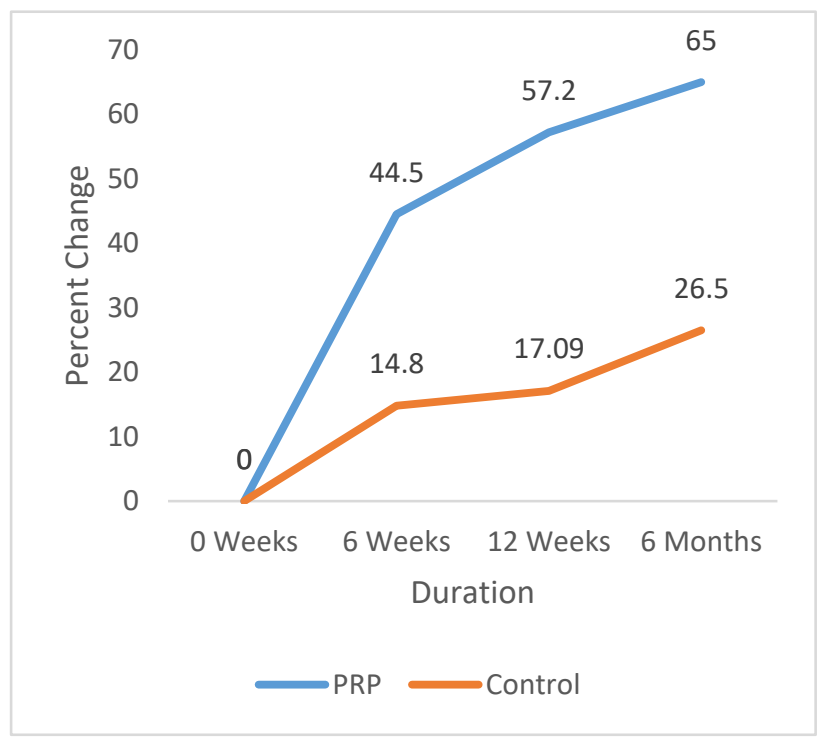

Figure 2: Percent change in VAS scores for patients in PRP injection (croup A) and control (croup B) over time.

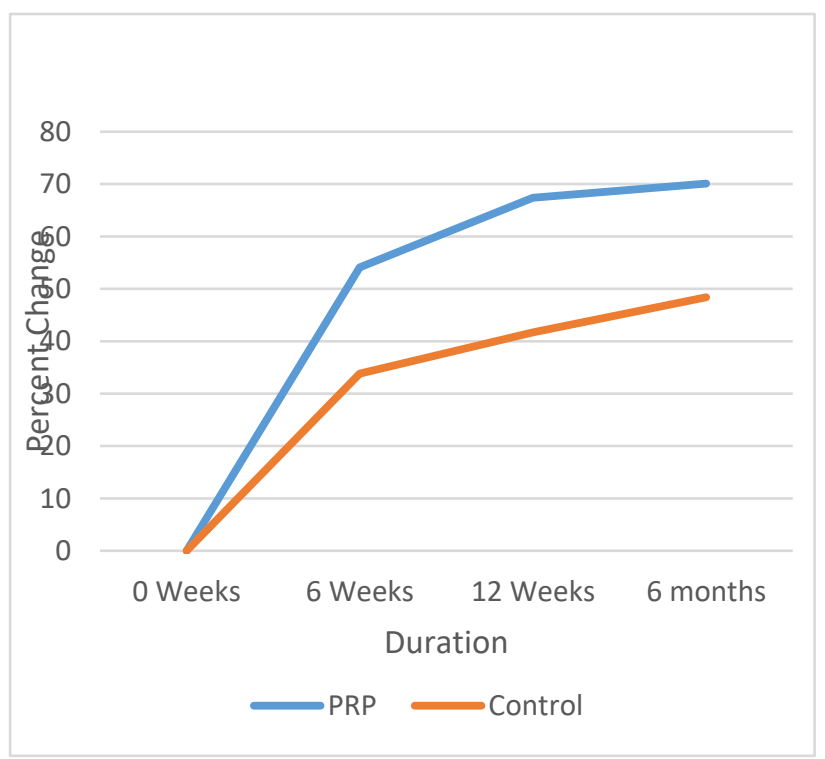

Figure 3: Percent change for PRTEE scores for patients in PRP injection (group A) and control (group B) over time. 
Table 1: VAS scores for patients with PRP and control group.

\begin{tabular}{|c|c|c|c|c|c|c|c|c|c|c|}
\hline Groups & $\begin{array}{l}\text { 0 } \\
\text { week }\end{array}$ & $\begin{array}{l}6 \\
\text { weeks }\end{array}$ & $\begin{array}{l}\% \\
\text { change }\end{array}$ & $\mathbf{P}$ & $\begin{array}{l}12 \\
\text { weeks }\end{array}$ & $\begin{array}{l}\% \\
\text { change }\end{array}$ & $\mathbf{P}$ & $\begin{array}{l}6 \\
\text { months }\end{array}$ & $\begin{array}{l}\% \\
\text { change }\end{array}$ & $\mathbf{P}$ \\
\hline $\begin{array}{l}\text { Group } \\
\text { A }\end{array}$ & 82.3 & 45.6 & 44.5 & 0.0036 & 35.2 & 57.2 & 0.001 & 28.8 & 65.0 & 0.001 \\
\hline $\begin{array}{l}\text { Group } \\
\text { B }\end{array}$ & 86.0 & 73.2 & 14.8 & 0.0034 & 71.3 & 17.09 & 0.002 & 63.2 & 26.5 & 0.001 \\
\hline
\end{tabular}

Table 2: PRTEE scores for patients of both groups.

\begin{tabular}{|c|c|c|c|c|c|c|c|c|c|c|}
\hline Groups & $\begin{array}{l}0 \\
\text { week }\end{array}$ & $\begin{array}{l}6 \\
\text { weeks }\end{array}$ & $\begin{array}{l}\% \\
\text { change }\end{array}$ & $\mathbf{P}$ & $\begin{array}{l}12 \\
\text { weeks }\end{array}$ & $\begin{array}{l}\% \\
\text { change }\end{array}$ & $\mathbf{P}$ & $\begin{array}{l}6 \\
\text { months }\end{array}$ & $\begin{array}{l}\% \\
\text { change }\end{array}$ & $\mathbf{P}$ \\
\hline Group A & 51.3 & 23.5 & 54.1 & 0.0034 & 16.7 & 67.4 & 0.004 & 15.3 & 70.1 & 0.002 \\
\hline Group B & 53.7 & 35.5 & 33.8 & 0.0036 & 31.3 & 41.7 & 0.003 & 27.7 & 48.4 & 0.002 \\
\hline
\end{tabular}

\section{DISCUSSION}

Chronic lateral epicondylar tendinopathy is a difficult condition to treat. The costs associated with TE are substantial in terms of both lost productivity and health care use. In many cases, it responds to conservative measures but in about $10-15 \%$ of cases, the symptoms continue to persist in spite of all conservative measures.

In this study we evaluate the effect of two different treatment modalities viz. needling and needling along with PRP injection. In our study, at 6 weeks both the groups showed significantly better results $(\mathrm{p}<0.01)$ than baseline values. At six weeks, percentage wise largest difference from the baseline value was seen in group A. Similar trends were seen at 3 months and 6 months follow up assessments. Patients in group A showed significantly better results when compared to those in group B at all the follow up visits. This indicated that needling combined with PRP injection was better when compared to needling alone.

Another observation was that in both the groups, improvement seen in the first 6 weeks was more than compared to the period between 3-6 months, but the results at 6 months was better than at 3 months.

Most commonly used procedure for lateral epicondylitis has been cortisone injections. A survey of 400 members of the American academy of orthopaedic surgeons found that 93\% had administered a corticosteroid injection for this type of problem. ${ }^{21}$ These injections have demonstrated only short term relief and can cause complications like tendon rupture and dermal atrophy. ${ }^{22,23}$ Studies by Gosens and Peerbooms and meta-analysis by $\mathrm{Mi}$ et al described that steroid injection may give better pain relief in the first months after injection, but after 2 years of follow-up the PRP group reported superior results. ${ }^{17,24}$ Comparable findings werealsodescribed by Gautam et al. ${ }^{25}$

Yadav and Behera et al reported after 3 months followup significant improvement in pain and function in a PRP group. $^{26,27}$
As the influence of conditioned plasma on TE remains controversial, some studies focused on the biologic effect of injecting PRP versus autologous blood injection (ABI). Creaney and Raeissadat et al. ${ }^{28,29}$ Reported no difference in pain scores between PRP and ABI, after 6 months and 12 months of injections. They found both methods to be equal in efficacy and recommended them when conservative treatment failed.

Arirachakaran et al in a meta-analysis, comparing PRP to autologous blood and steroid injection found that response to PRP was favorable when compared to steroid injection for pain management and for patient reported outcomes. Furthermore, it was reported that PRP injection did not have the complications associated with a steroid injection such as skin atrophy, discoloration, and secondary tendon tears. $^{30}$

Chou et al in a meta-analysis comparing ABI, PRP, and corticosteroid injections, found no significant difference between PRP and ABI, with both having superior pain scores to corticosteroid injections. ${ }^{31}$

Surgery has been recommended to patients who fail to respond to these measures. Most of the surgical literature for such patients have case series of fewer than 50 patients (type 4 evidence), reporting varying degrees of success ranging from 80 to $90 \% .{ }^{32}$ Moreover, up to $28 \%$ of such patients may complain of persistent symptoms, and $9 \%$ report moderate to severe pain five years after surgery. ${ }^{33}$ Rha et al also noted that clinical effect of the platelet-rich plasma injection was superior to the dry needling from six weeks to six months after initial injection $(\mathrm{p}<0.05) .{ }^{34}$ At six months the mean shoulder pain and disability index was $17.7 \pm 3.7$ in the platelet-rich plasma group versus $29.5 \pm 3.8$ in the dry needling group $(\mathrm{p}<0.05)$.

Two original papers, however, reported higher incidence of local pain after PRP administration. ${ }^{35,36}$ The randomized prospective study published by Palacio et al reported that there was no significant difference in patients' improvement when treated with PRP, dexamethasone and neocaine. ${ }^{37}$ Two papers have also reported no significant 
difference in pain scores between PRP and steroids. ${ }^{38,39}$ The lack of standardization of PRP preparations, described by Mishra et al could partially justify the differences in reported outcomes among the studies. ${ }^{40}$

PRP may give faster relief as reported by Thanasas et al in 6 weeks after an injection, patients in the PRP group had significantly lower pain scores versus those in the ABI group. ${ }^{41}$

Lim et al reported that needling when combined with PRP injection gives favourable results versus physiotherapy. ${ }^{42}$ Similarly, beneficial results of were also reported by Gaspar et al reported sustained good outcomes with PRP injections and concomitant needling at a mean follow-up of over 3 years. $^{43}$

Mishra et al who compared the results of extensor tendon needling alone or in association with PRP injections in a multicenter randomized controlled trial, found no significant differences at 12 weeks, but clinically meaningful improvements were found in patients treated with leukocyte-enriched PRP compared with an active control group at 24 weeks. ${ }^{44}$

The limitation of our study was small sample size, shorter follow up period while the strength being its randomised nature and double blinded study.

\section{CONCLUSION}

The combination of PRP injection along with needling is a safe, effective procedure in the management of tennis elbow. We recommend it use in resistant cases of TE not responding to medications.

\section{Funding: No funding sources}

Conflict of interest: None declared

Ethical approval: The study was approved by the institutional ethics committee

\section{REFERENCES}

1. Peerbooms JC, Sluimer J, Bruijn DJ, Gosens T. Positive effect of autologous platelet concentrate in lateral epicondylitis in a double- blind randomized controlled trial. Am J Sports Med. 2010;38(2):255-32.

2. Kraushaar BS, Nirschl RP. Tendinosis of the elbow (tennis elbow). Clinical features and findings of histological, immunohistochemi-cal, and electron microscopy studies. J Bone Joint Surg Am. 1999;81(2):259-78.

3. Verhaar JA. Tennis elbow. Anatomical, epidemiological and therapeutic aspects. Int Orthop. 1994;18(5):263-7.

4. Chard MD, Hazleman BL. Tennis elbow-a reappraisal. Br J Rheumatol. 1989;28(3):186-90.

5. Nirschl RP, Pettrone FA. Tennis elbow: the surgical treatment of lateral epicondylitis. J Bone Joint Surg Am. 1979;61(6A):832-9.

6. Ljung BO, Alfredson H, Forsgren S. Neurokinin 1- receptors and sensory neuropeptides in tendon insertions at the medial and lateral epi- condyles of the humerus: studies on tennis elbow and medial epicondylalgia. J Orthop Res. 2004;22(2):321-7.

7. Zeisig E, Ohberg L, Alfredson H. Extensor origin vascularity related to pain in patients with tennis elbow. Knee Surg Sports Traumatol Arthrosc. 2006;14(7):659-63.

8. Major HP. Lawn-tennis elbow [letter]. Br Med J. 1883;2:557.

9. Coppinger JA, Cagney G, Toomey S. Characterization of the proteins released from activated platelets leads to localization of novel platelet proteins in human atherosclerotic lesions. Blood. 2004;103(6):2096-104.

10. Mishra A, Randelli P, Barr C, Talamonti T, Ragone V, Cabitza P. Platelet-rich plasma and the upper extremity. Hand Clin. 2012;28(4):481-91.

11. Mishra A, Woodall J Jr, Vieira A. Treatment of tendon and muscle using platelet-rich plasma. Clin Sports Med. 2009;28(1):113-25.

12. Kajikawa Y, Morihara T, Sakamoto H. Platelet rich plasma enhances the initial mobilization of circulationderived cells for ten- don healing. J Cell Physiol. 2008;215(3):837-45.

13. Virchenko O, Aspenberg P. How can one platelet injection after tendon injury lead to a stronger tendon after 4 weeks? Interplay between early regeneration and mechanical stimulation. Acta Orthop. 2006;77(5):806-12.

14. Visser LC, Arnoczky SP, Caballero O, Kern A, Ratcliffe A, Gardner KL. Growth factor-rich plasma increases tendon cell proliferation and matrix synthesis on a synthetic scaffold: an in vitro study. Tissue Eng Part A. 2010;16(3):1021-9.

15. Wang X, Qiu Y, Triffitt J, Carr A, Xia Z, Sabokbar A. Proliferation and differentiation of human tenocytes in response to platelet rich plasma: an in vitro and in vivo study. J Orthop Res. 2012;30(6):982-90.

16. Mishra A, Pavelko T. Treatment of chronic elbow tendinosis with buffered platelet-rich plasma. Am J Sports Med. 2006;33(11):1774-8.

17. Gosens T, Peerbooms JC, van Laar W, den Oudsten BL. Ongoing positive effect of platelet-rich plasma versus corticosteroid injection in lateral epicondylitis: a doubleblind randomized controlled trial with 2-year follow-up. Am J Sports Med. 2011;39(6):1200-8.

18. Peerbooms JC, Sluimer J, Bruijn DL, Gosens T. Positive effect of an autologous platelet concentrate in lateral epicondylitis in a double- blind randomized controlled trial: platelet-rich plasma versus cortico- steroid injection with a 1-year follow-up. Am J Sports Med. 2010;38(2):255-62.

19. McShane JM, Shah VN, Nazarian LN. Sonographically guided percutaneous needle tenotomy for treatment of common extensor tendinosis in the elbow: is a corticosteroid necessary? J Ultrasound Med. 2008;27(8):1137-44.

20. Hill JJ, Trapp RG, Colliver JA. Survey on the use of corticosteroid injections by orthopedists. Contemp Orthop. 1989;18:39-45.

21. Mac Dermid JC. Outcome evaluation in patients with 
elbow pathology: issues in instrument development and evaluation. J Hand Ther. 2001;14:105-14.

22. Zhang J, Keenan C, Wang JH. The effects of dexamethasone on human patellar tendon stem cells: implications for dexamethasone treatment of tendon injury. J Orthop Res. 2013;31(1):105-10.

23. Krogh TP, Fredberg U, Stengaard-Pedersen K, Christensen R, Jen- sen P, Ellingsen T. Treatment of lateral epicondylitis with platelet- rich plasma, glucocorticoid, or saline: a randomized, double-blind, placebo-controlled trial. Am J Sports Med. 2013;41(3):625-35.

24. Mi B, Liu G, Zhou W, Lv H, Liu Y, Wu Q et al. Platelet rich plasma versus steroid on lateral epicondylitis: metaanalysis of randomized clinical trials. Phys Sportsmed. 2017;45(2):97-104.

25. Gautam VK, Verma S, Batra S, Bhatnagar N, Arora S. Platelet-rich plasma versus corticosteroid injection for recalcitrant lateral epicondylitis: clinical and ultrasonographic evaluation. J Orthop Surg (Hong Kong). 2015;23(1):1-5.

26. Yadav R, Kothari SY, Borah D. Comparison of local injection of platelet rich plasma and corticosteroids in the treatment of lateral epicondylitis of humerus. J Clin Diagn Res. 2015;9(7):RC05-7.

27. Dhillon PBM, Aggarwal S, Marwaha N, Prakash M. Leukocyte- poor platelet-rich plasma versus bupivacaine for recalcitrant lateral epicondylar tendinopathy. J Orthop Surg (Hong Kong). 2015;23(1):6-10.

28. Creaney L. Platelet-rich plasma and the biological complexity of tissue regeneration. Br J Sports Med. 2011;45(8):611.

29. Raeissadat SA, Rayegani SM, Hassanabadi H, Rahimi R, Sedighipour L, Rostami K. Is platelet-rich plasma superior to whole blood in the management of chronic tennis elbow: one-year randomized clinical trial. BMC Sports Sci Med Rehabil. 2014;6(1).

30. Arirachakaran A, Sukthuayat A, Sisayanarane T, Laoratanavoraphong S, Kanchanatawan W, Kongtharvonskul J. Platelet-rich plasma versus autologous blood versus steroid injection in lateral epicondylitis: systematic review and network metaanalysis. J Orthop Traumatol. 2016;17(2):101-12.

31. Chou LC, Liou TH, Kuan YC, Huang YH, Chen HC. Autologous blood injection for treatment of lateral epicondylosis: a meta- analysis of randomized controlled trials. Phys Ther Sport. 2016;18:68-73.

32. Lo MY, Safran MR. Surgical treatment of lateral epicondylitis: a systematic review. Clin Orthop Relat Res. 2007;463:98-106.

33. Cohen MS, Romeo AA. Open and arthroscopic management of lateral epicondylitis in the athlete. Hand Clin. 2009;25:331-8.

34. Rha DW, Park GY, Kim YK, Kim MT, Lee SC.
Comparison of the therapeutic effects of ultrasoundguided platelet-rich plasma injection and dry needling in rotator cuff disease: a randomized controlled trial. Clin Rehabil. 2012.

35. Lebiedziński R, Synder M, Buchcic P, Polguj M, Grzegorzewski A, Sibinski M. A randomized study of autologous conditioned plasma and steroid injections in the treatment of lateral epicondylitis. Int Orthop. 2015;39(11):2199-203.

36. Krogh TP, Bartels EM, Ellingsen T, StengaardPedersen K, Buchbinder R, Fredberg $U$ et al. Comparative effectiveness of injection therapies in lateral epicondylitis: a systematic review and network meta-analysis of randomized controlled trials. Am J Sports Med. 2013;41(6):1435-46.

37. Palacio EP, Schiavetti RR, Kanematsu M, Ikeda TM, Mizobuchi RR, Galbiatti JA. Effects of platelet-rich plasma on lateral epicondylitis of the elbow: prospective randomized controlled trial. Rev Bras Ortop. 2016;51(1):90-5.

38. Mi B, Liu G, Zhou W, Lv H, Liu Y, Wu Q et al. Platelet rich plasma versus steroid on lateral epicondylitis: metaanalysis of randomized clinical trials. Phys Sports med. 2017;45(2):97-104.

39. Khaliq A, Khan I, Inam M, Saeed M, Khan H, Iqbal MJ. Effectiveness of platelets rich plasma versus corticosteroids in lat- eral epicondylitis. J Pak Med Assoc. 2015;65(11,3):S100-4.

40. Mishra A, Harmon K, Woodall J Jr, Vieira A. Sports medicine applications of platelet rich plasma. Curr Pharm Biotechnol. 2012;13(7):1185-95.

41. Mishra A, Harmon K, Woodall J Jr, Vieira A. Sports medicine applications of platelet rich plasma. Curr Pharm Biotechnol. 2012;13(7):1185-95.

42. Lim W, Park SH, Kim B, Kang SW, Lee JW, Moon YL. Relationship of cytokine levels and clinical effect on platelet- rich plasma-treated lateral epicondylitis. J Orthop Res. 2018;36(3):913-20.

43. Gaspar MP, Motto MA, Lewis S, Jacoby SM, Culp RW, Lee Osterman A, et al. Platelet-rich plasma injection with percutaneous needling for recalcitrant lateral epicondylitis: comparison of tenotomy and fenestration techniques. Orthop J Sports Med. 2017;5(12):232596711774207.

44. Mishra AK, Skrepnik NV, Edwards SG, Jones GL, Sampson S, Vermillion DA, et al. Efficacy of plateletrich plasma for chronic tennis elbow: a double-blind, prospective, multicenter, randomized controlled trial of 230 patients. Am J Sports Med. 2014;42(2):463-71.

Cite this article as: Sharma V, Chandak V.

Comparison of efficacy of needling and a combination of needling and platelet rich plasma in relieving pain and improving function in patients of tennis elbow: a prospective, randomized, double blinded, placebo controlled clinical trial. Int J Res Orthop 2021;7:258-63. 